\title{
RAZGLEDI
}

\section{NEKAJ MISLI O KONCEPTU PROŽNOSTI V GEOGRAFIJI NARAVNIH NESREČ}

\author{
AVTORJA \\ dr. Blaž Komac \\ Znanstvenoraziskovalni center Slovenske akademije znanosti in umetnosti, Geografski inštitut Antona Melika, \\ Gosposka ulica 13, SI - 1000, Ljubljana, Slovenija \\ blaz.komac@zrc-sazu.si
}

\section{Lucija Lapuh}

Znanstvenoraziskovalni center Slovenske akademije znanosti in umetnosti, Geografski inštitut Antona Melika, Gosposka ulica 13, SI - 1000, Ljubljana, Slovenija

lucija.lapuh@zrc-sazu.si

\section{DOI: $10.3986 / G V 86103$}

UDK: $91: 504.4$

COBISS: 1.02

\section{IZVLEČEK}

\section{Nekaj misli o konceptu prožnosti v geografiji naravnih nesreč}

Koncept prožnosti se $v$ zadnjem času uveljavlja kot pripomoček za razumevanje pokrajinske stvarnosti. Čeprav so ga uporabljali že $v$ antiki, pojem $v$ sodobnem pomenu izhaja iz fizike, kjer označuje lastnost materiala, da se ob motnji povrne $v$ prvotno lego. V sedemdesetih letih prejšnjega stoletja so ga uporabili $v$ biologiji, potem pa je počasi prešel na druge vede. V geografiji se je uveljavil v zadnjem desetletju, zlasti na področju ekonomske geografije, $v$ zadnjem času pa tudi na področju naravnih nesreč. V članku predstavljamo naravno- in družbenogeografske kazalnike s katerimi merimo prožnost pri naravnih nesrečah in iz njih izračunane indekse, ki so nam lahko v pomoč pri razumevanju geografske stvarnosti.

\section{KLJUČNE BESEDE}

geografija, geomorfologija, naravne nesreče, prožnost, ranljivost

\begin{abstract}
Some thoughts on the concept of resilience in geography of natural hazards

The concept of resilience has recently been gaining ground as a tool for understanding the landscape. Although it was already used in antiquity, the concept in its modern sense derives from physics, where it designates a characteristic of the material that is returned to its original position after a fault. The term was first used in biology in the seventies of the past century, and then it slowly moved to other sciences. It has been established in geography over the last decade, especially in the field of economic geography, and recently in the field of natural hazards. In this paper we present different natural-and social-geographic indicators to measure resilience of natural hazards and from derived indices that can help us better understand geographical environment.
\end{abstract}

\section{KEY WORDS}

geography, geomorphology, natural hazards, resilience, vulnerability

Uredništvo je prispevek prejelo 1. oktobra 2014. 


\section{Uvod}

Po geografskem pojmovanju so naravne nesreče sestavni del pokrajine. To so procesi in pojavi na zemeljskem površju, ki jih povzročajo izjemne naravne okoliščine. V zmernotoplem pasu so to običajno vremenski, hidrološki in geološki pojavi, kot so poplave, neurja, potresi in požari. Običajno so to intenzivni, toda redki pojavi, zato jih dojemamo kot nekaj izjemnega. Odtod izhaja izraz naravna »nesreča«, ki je resda nekoliko nerodno izbran, če opisuje pojave, ki jih na primer v angleščini označuje izraz natural hazards, a ga uporabljamo, ker je že dodobra uveljavljen.

Vtisnjenost naravnih nesreč v pokrajino oziroma njihov pokrajinotvorni prispevek med drugim dokazuje nenehno prilagajanje družbe spreminjajočim se naravnim razmeram skozi zgodovino. Do industrijske dobe je imela družba omejene, čeprav tudi že učinkovite možnosti za prilagajanje naravnim dogodkom, kot so: obdelava zemljišč, pridobivanje in izboljševanje zemljišč s požiganjem gozda, terasiranjem, komasacijami in melioracijami, gradnjo namakalnih sistemov, reguliranjem vodotokov ter pridobivanjem rudnin in energije. S tehnološkim razvojem je prišlo tudi do sprememb v razmerju družbe do naravnih nesreč in do premika od prilagajanja k obvladovanju. Obvladovanje ima svoje omejitve, zato je bolj primerno, da se naravnim dogodkom poskušamo prilagoditi, kjer pa to ni možno, upravljamo z njimi oziroma njihovim potekom. Tako v današnji pokrajini odseva celoten dosedanji razvoj človekovega odnosa do naravnogeografskih prvin oziroma naravnih nesreč in različnih načinov sobivanja, obvladovanja ali upravljanja z njimi (Natek 2002; Komac 2009).

Naravne nesreče tudi v »razvitih « evropskih državah povzročajo veliko škodo, kar je pogosto posledica neustreznega prostorskega načrtovanja. Dodatno $\mathrm{k}$ temu prispevajo podnebne spremembe, ki spreminjajo jakost in pogostost naravnih nesreč. Tako je eden od večjih izzivov slovenske družbe dolgoročno zmanjšati finančne posledice naravnih nesreč. V Sloveniji so naravne nesreče v obdobju od 1991 do 2008 (do tega leta je Statistični urad Republike Slovenije zbiral podatke o škodi) povzročile za 1,6 milijarde evrov neposredne škode ali približno 47 evrov na prebivalca letno. Skupna gospodarska škoda je še približno petkrat večja (Zorn in Komac 2011). Namesto preventivi namenjamo velika sreds-

Slika 1: Na cerkvi sv. Lamberta v Rutu je upodobljena Riba Faronika, ki v slovenski mitologiji nosi Zemljo in s premikanjem repa povzroči potres ali poplavo.

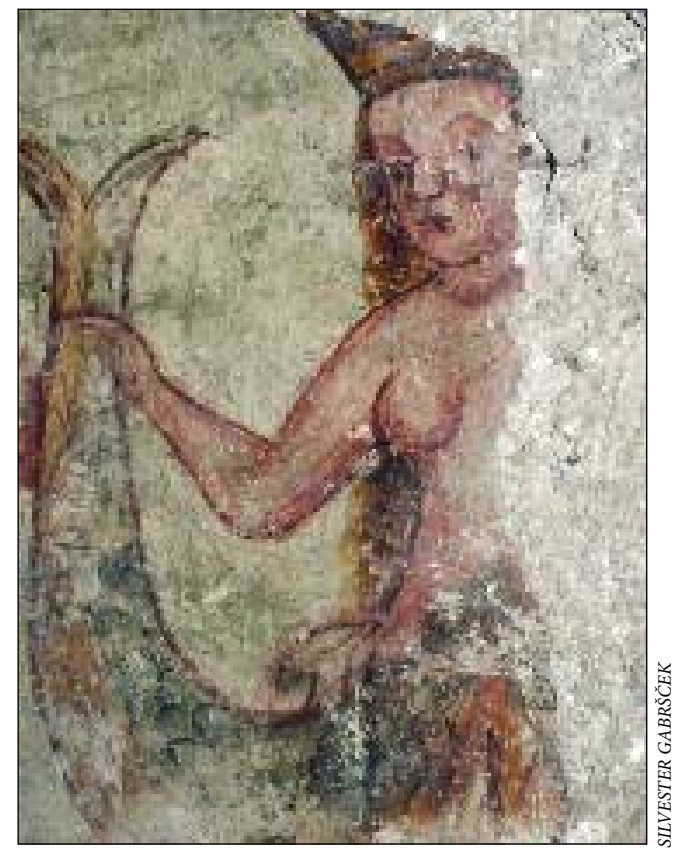




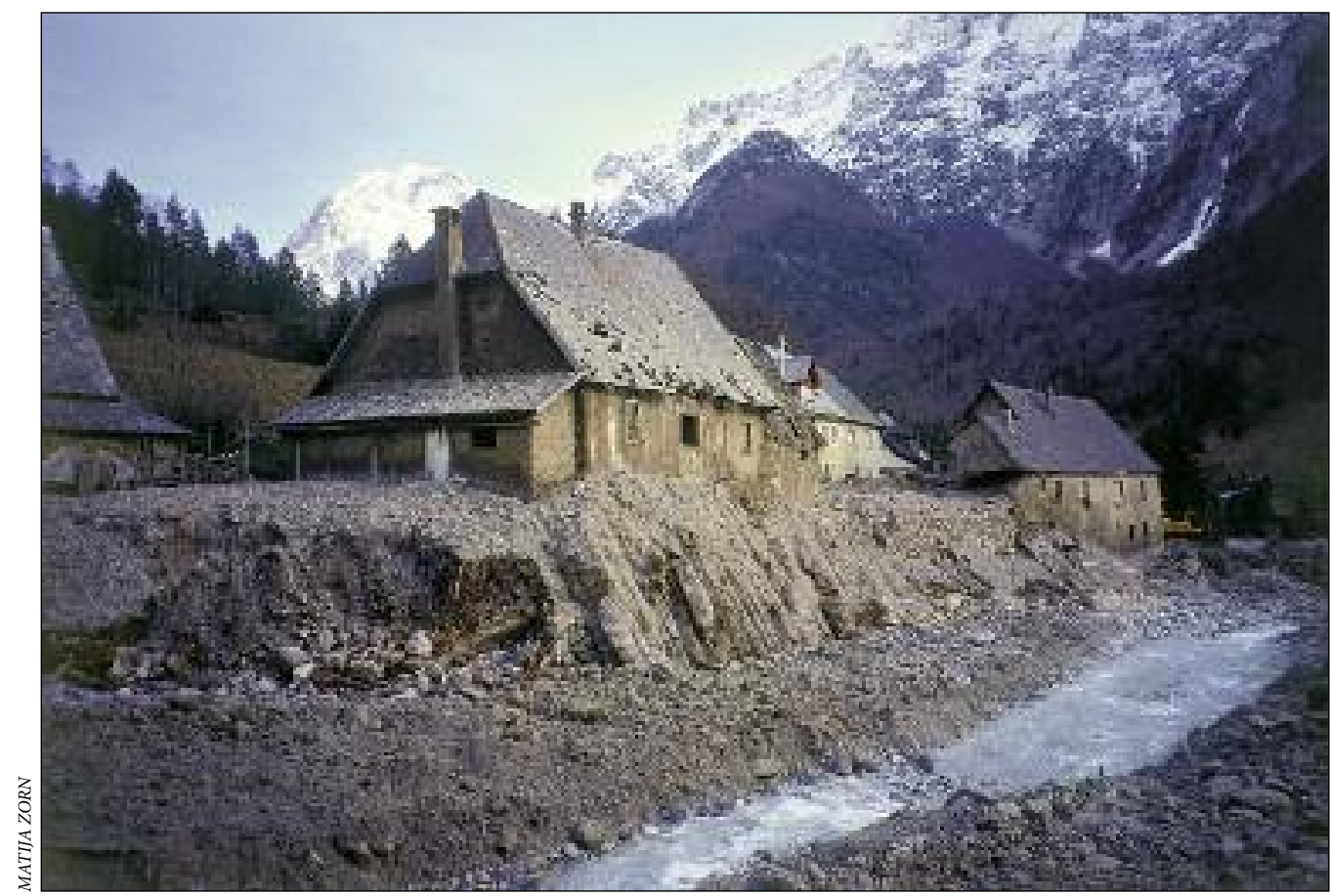

Slika 2: Drobirski tokv Logu pod Mangartom je odločno presegel družbenogeografsko prožnost pokrajine, medtem ko je šlo z naravnogeografskega vidika za izjemen, a vendarle pričakovan pojav.

tva obnovi po naravnih nesrečah. V sosednji Italiji so na primer med letoma 1980 in 2005 porabili 34 evrov na prebivalca letno samo za obnovo po naravnih nesrečah (Lunino 2005).

V celoti gledano se prizadetim $\mathrm{z}$ različnimi mehanizmi povračil povrne približno desetina škode. Ker pa je znano, da se sredstva, vložena v preventivo, dolgoročno povrnejo tudi desetkratno, bi morali v preventivi bolj kot strošek videti dolgoročno naložbo (Zorn, Komac in Kumelj 2012; Building our nation's ... 2013; Turconi, Nigrelli in Conte 2014). Za dosego tega cilja se je v zadnjem času uveljavil koncept prožnosti, ki temelji na kompleksnosti pokrajine kot družbeno-naravnega sistema ter upošteva prostorski in časovni vidik. Uporaben je pri oceni stopnje ranljivosti in prožnosti posameznih regij ter tako izboljšuje upravljanje območij s prilagajanjem. Prilagajanje na dolgi rok je stalen, vseživljenjski proces, ki v splošnem edino omogoča prožnost (Cannon 2008; Schoutenova s sodelavci 2012). Obstajajo različni pristopi razlaganja prožnosti: inženirski, ekološki in družbeno-gospodarski. V prispevku so predstavljeni naravno- in družbenogeografski kazalniki merjenja prožnosti pri naravnih nesrečah.

\section{Koncept prožnosti v geografiji}

V znanosti je prožnost razmeroma nov koncept, širše gledano pa je znan že stoletja. Termin so uporabljali že v antiki, med drugimi Ovid, Seneka starejši, Plinij starejši in sv. Hieronim (Alexander 2013). V sodobni znanosti je razumljena inderdisciplinarno. Beseda izhaja iz latinskega glagola resilire, kar pomeni 'skočiti nazaj, odskočiti'. Z njo označujemo sposobnost prilagajanja razmeram v naravi, pa tudi na finančnem, organizacijskem ali obrambnem področju (Alexander 2013). 
V fiziki pomeni prožnost sposobnost materiala (na primer kovine), da ob deformaciji absorbira energijo, ob razbremenitvi pa se vrne na stanje pred deformacijo. Merimo jo z močjo deformacije in elastičnostjo materiala. V nasprotju s prožnostjo je odpornost/trdota (ang. toughness) sposobnost materiala, da absorbira energijo in omogoča, da na pritisk še ne spremeni oblike. Ko je pritisk premočan, se material deformira in se potem ni zmožen vrniti v prvotno obliko, kot je značilno pri prožnem (Campbell 2008).

V naravoslovju so izraz prvič uporabili v ekologiji za (Holling 1973): »... mero sposobnosti ekosistema za vključitev spremembe in nadaljnji obstoj ... « oziroma »... vztrajnost odnosov znotraj ekosistema... «. Prožnost označujejo tudi kot sposobnost sistema, da ne spremeni obstoječe oblike, da absorbira šok oziroma motnjo oziroma se motnji prilagodi in pri tem ne spremeni svojih bistvenih lastnosti, hkrati pa še vedno ohranja svojo funkcijo. Nekateri poudarjajo samoorganizacijsko prožnost sistemov (Walker s sodelavci 2002; Folke s sodelavci 2002; Manyena 2006; Raco in Street 2012) in jo vključujejo v celovit sistem odgovora geomorfnega sistema na spremembe: odziv-odpornost-prožnost-povratni učinki.

Prožnost je v temelju "geografska kategorija« (Hewitt 1997). Zato ni presenetljivo, da se je pojem iz prvotne rabe v ekologiji, fiziki in gradbeništvu ter psihiatriji razširil na področje geografije in znotraj nje po letu 1990 tudi na področje geomorfologije in naravnih nesreč. Večjo veljavo na področju naravnih nesreč je pojem doživel zaradi pozitivnega pomena v primerjavi s pojmom ranljivost (Galderisi in Ferrara 2013). Opredelitev natančnega razmerje med obema pojmoma je še predmet razprav. Prožnost razumejo bodisi kot nasprotje ranljivosti (Fortune in Peters 1995) bodisi kot neodvisna koncepta, ki pa se deloma prekrivata (Paton in Johnston 2006).

Pojem prožnost vzpostavlja jasno zvezo med naravnimi nevarnostmi in odzivom družbe ter gospodarstva, zato je pridobil še družbenogeografski pomen (Adger 2000; Zehetmair 2012; Galderisi in

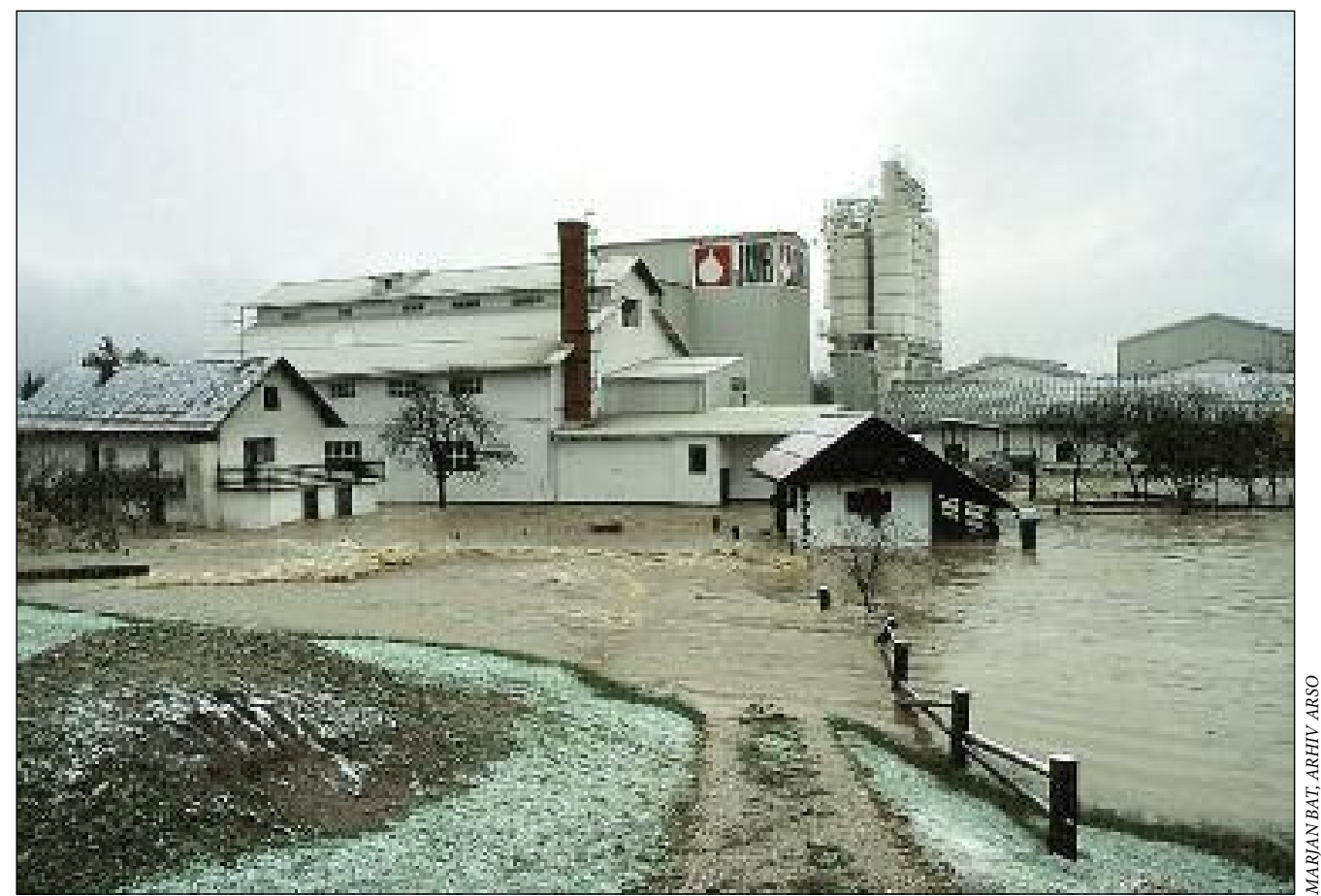

Slika 3: Številne javne ustanove, kot so šole in mnoga podjetja so gradili na nevarnih območjih. Ali dobiček presega škodo, ki jo ponekod redno povzročajo naravne nesreče? 
Ferrara 2013; Zhou s sodelavci 2010). Z družbenega vidika pomeni prožnost »... odziv družbene skupnosti, ustanov ali gospodarskih sistemov in subjektov na spremembe in prilagoditve $v$ funkciji nadaljnjega obstoja« (Klein, Nicholls in Thomalla 2003). Družbena prožnost je v pokrajini vidna predvsem prek participativnega načrtovanja dejavnosti in rabe prostora $\mathrm{v}$ prostorskem, regionalnem in urbanističnem načrtovanju ter pri drugih načinih sobivanja z naravnimi nesrečami (Lu in Stead 2013; Rouillard s sodelavci 2014).

\section{Kazalniki, ki opredeljujejo prožnost pri naravnih nesrečah}

Prožnost določenega kraja ali območja je težko izmeriti, ker procesi v pokrajini delujejo hkrati na različnih prostorskih ravneh, zanje pa so značilne povratne zveze, ki se spreminjajo tudi v času. Poleg tega imajo različne vrste naravnih nesreč različne učinke.

Inženirski pristop meri prožnost $\mathrm{z}$ vidika časa, ki je potreben, da se sistem vrne v ravnovesno lego. Soroden je ideji elastičnosti in opisuje sposobnost sistema, da absorbira šok. Weichselgartner in Kelman (2014) pa se na primer sprašujeta, zakaj bi si ljudje sploh želeli vrnitve na prvotno stanje pred spremembo, saj je zanj očitno značilna večja ranljivost in odsotnost trajnostnosti.

Ekološki pristop meri prožnost s sposobnostjo sistema, da absorbira spremembe, preden se poruši ravnovesje, oziroma se sistem premakne v novo ravnovesno stanje (Martin 2012). Tem večji šok lahko absorbira, prožnejši je sistem.

V geomorfologiji prožnost merimo s stopnjo obnove sistema v primerjavi z začetnim stanjem. Tako predpostavljamo, da se sistem ne povrne vedno v začetno lego. Ker so geomorfni pojavi v času bolj stabilni, čeprav se robni pogoji spreminjajo, zanje ni nujen statičen pogled, ki ga zahteva inženirski pristop, ki obravnava strukture s krajšo življenjsko dobo, temveč je primernejši ekološki pogled.

Družbeno-gospodarski pristop prožnost meri s količino sprememb, ki jih sistem lahko prenese in stopnjo, do katere se lahko samoorganizira. Bistvena razlika med ekološko in družbeno prožnostjo je, da je človeška družba zmožna predvidevanja in načrtovanja, s tem pa prilagajanja in upravljanja (Kulig in Hanson 1996; Brundsen 2001; Holling 2004; Woodroffe 2006). Razumljivo obsega geografski pogled na prožnost oba vidika: analizo prožnosti naravnih in družbenih značilnosti.

Nekateri raziskovalci so že kvantitativno opredelili prožnost. Tako sta na primer Hewitt in Burton (1971) prispevala pionirsko delo na področju prostorskih vidikov nevarnosti, Cutterjeva je s sodelavci (2008) izdelala model prožnosti $z$ vidika interakcije med učinkom nesreče in absorpcijsko sposobnostjo določenega kraja (DROP - disaster resilience of place). Chen je s sodelavci (2008) izdelal model prožnosti v vzpetih pokrajinah, Zhou je s sodelavci (2010) predstavil kompleksno krajevno analizo prožnosti kmetijske pokrajine z vidika suše in količine pridelka, temelječo na poglobljenih intervjujih, Francis in Bekerova (2014) pa prožnost infrastrukturnih sistemov.

\subsection{Naravnogeografski kazalniki prožnosti}

Pokrajine in njihove prvine lahko prostorsko in časovno medsebojno primerjamo s pomočjo različnih kazalnikov. Z njihovo pomočjo spoznamo delovanje procesov, vplivne dejavnike ter njihove vzroke in povratne zveze ter tako izmerimo oziroma ocenimo prožnost pokrajin (Bruneau s sodelavci 2003; Cutter s sodelavci 2008; Ainuddin in Routray 2012; Orencio in Fujii 2013).

Pri tem so pomembni predvsem dejavniki, ki razkrivajo pogostost naravnih procesov, njihovo intenzivnost ter odzivnost naravnih sistemov nanje. Tako traja na primer čas obnove po premikih sedimentov od nekaj let do več desetletij ali stoletij, odvisen pa je od podnebja, obnovljivosti rastja, transporta sedimentov, vodnega pretoka in njihovih medsebojnih razmerij ter delovanja človeka, predvsem rabe zemljišč (Zorn in Komac 2009). Procesi potekajo na različnih velikostnih ravneh, poleg tega so geomorfološke spremembe $\mathrm{z}$ vidika družbe počasne. Procesi, ki jih dojemamo kot naravne nesreče, pa so hitri in 
so nekakšen pospešek običajnega hidro-geomorfnega dogajanja. Naravne nesreče so zato posebej zanimive za preučevanje, saj z njimi dobimo vpogled v sicer počasnejše dogajanje v pokrajini. V geografiji so redke raziskave naravnogeografske prožnosti, saj večina upošteva le prožnost biotskega sistema. Več je raziskav, ki upoštevajo tudi družbeni vidik.

Naravnogeografski kazalniki vključujejo opredelitev kazalnikov nevarnosti (magnituda, pogostost, trajanje, hitrost pojavljanja, obseg in koncentracija v prostoru), opredelitev ranljivosti pokrajine ter potencialnih pospeševalcev in zaviralcev pojavov. Na podlagi tega določimo geomorfne posledice kot funkcijo odziv-odpornost-prožnost-povratni učinki. Tako obsega odziv reakcijski in relaksacijski čas, odpornost pomeni sposobnost sistema, da se izogne ali minimalizira odziv na zunanje spremembe (motnje), prožnost pa označuje dinamično stabilnost oziroma konvergentno sposobnost sistema, da si opomore od motnje in vzpostavi novo ravnovesno stanje. Omenjeni odzivi na motnje se med seboj prepletajo in ustvarjajo povratne učinke.

Med družbenogeografskimi kazalniki, ki vplivajo na prožnost, izpostavljamo rabo tal in njene spremembe s poudarkom na zelenih površinah ter varovalnih gozdovih, med naravnogeografskimi kazalniki pa podnebne kazalnike, stopnjo transporta sedimentov $\mathrm{v}$ povezavi $\mathrm{z}$ različnimi naravnimi nevarnostmi in erozije, delež neprepustnih kamnin in sposobnost obnavljanja rastlinstva (Petek in Gabrovec 2002; Mikoš, Fazarinc in Ribičič 2006; Zorn in Komac 2009; Geršič s sodelavci 2014).

\subsection{Družbenogeografski kazalniki prožnosti}

Družbenogeografska prožnost obsega kvalitativni ali kvantitativni opis značilnosti družbe, razmerij $\mathrm{v}$ družbi in odzivnosti gospodarstva na krizne dogodke ter predvsem prilagoditev, ki se zrcali v diverzifikaciji dejavnosti in dohodkov (Ellis 1998; Major 2003; Schelfaut s sodelavci 2011; Mavhura s sodelavci 2013). Nabor družbenogeografskih kazalnikov obsega (Perrow 1999; Tobin 1999; Höppner, Buchecker in Bründl 2010; Kozina 2010; Martin 2012; Price-Robertson in Knight 2012; Rose in Krausmann 2013; Komac, Zorn in Kušar 2012):

- družbene kazalnike: demografski kazalniki, stopnja izobrazbe, zdravstvena oskrba, gostota poselitve, članstvo v društvih, znanje jezikov,

- gospodarske kazalnike: višina dohodkov in njihovi viri, stopnja zaposlenosti po panogah, premoženje gospodinjstev in lastništvo nepremičnin, javna sredstva, dobiček podjetij,

- fizične kazalnike: lega stavb, število razpoložljivih sredstev (avtomobili, zasilne postelje),

- prostorsko-načrtovalske kazalnike: razpoložljivost prostorskih načrtov, starost stavb,

- institucionalne kazalnike: komuniciranje ob nesreči, ozaveščanje, storitve občine, vodenje, formalne in neformalne socialne mreže, zaupanje, vključenost, informiranost, lastništvo nepremičnin, izkušnje s preteklimi naravnimi nesrečami, delovanje služb za prvo pomoč in število zdravnikov, obstoj načrtov ogroženosti zaradi naravnih nesreč, sodelovanje in stalnost delovanja ustanov na področju varstva pred naravnimi nesrečami, obstoj alarmnih sistemov, z naravnimi nesrečami povezana zemljepisna imena na obravnavanih območjih in

- infrastrukturne/tehnične kazalnike: število in gostota javnih zgradb, potek ter dolžina prometne in druge ključne infrastrukture (vodovod, električna napeljava, plinovod) ter prometna dostopnost, število podjetij in storitvenih dejavnosti ter njihova povezanost.

\subsection{Nekaj primerov raziskav prožnosti ob naravnih nesrečah}

Pri izboru meril je treba upoštevati veljavnost, občutljivost, cenovno in prostorsko dostopnost podatkov, izvedljivost metode in njeno relevantnost, pa tudi pripravnost za geografski prikaz rezultatov (Birkmann 2006) v geografskem informacijskem sistemu.

Tako sta Orencio in Fujii (2013) na temelju analitičnega hierarhičnega procesa, v katerem sta paroma primerjala različne alternative, in s pomočjo Delfi metode razvila krajevni indeks prožnosti na 


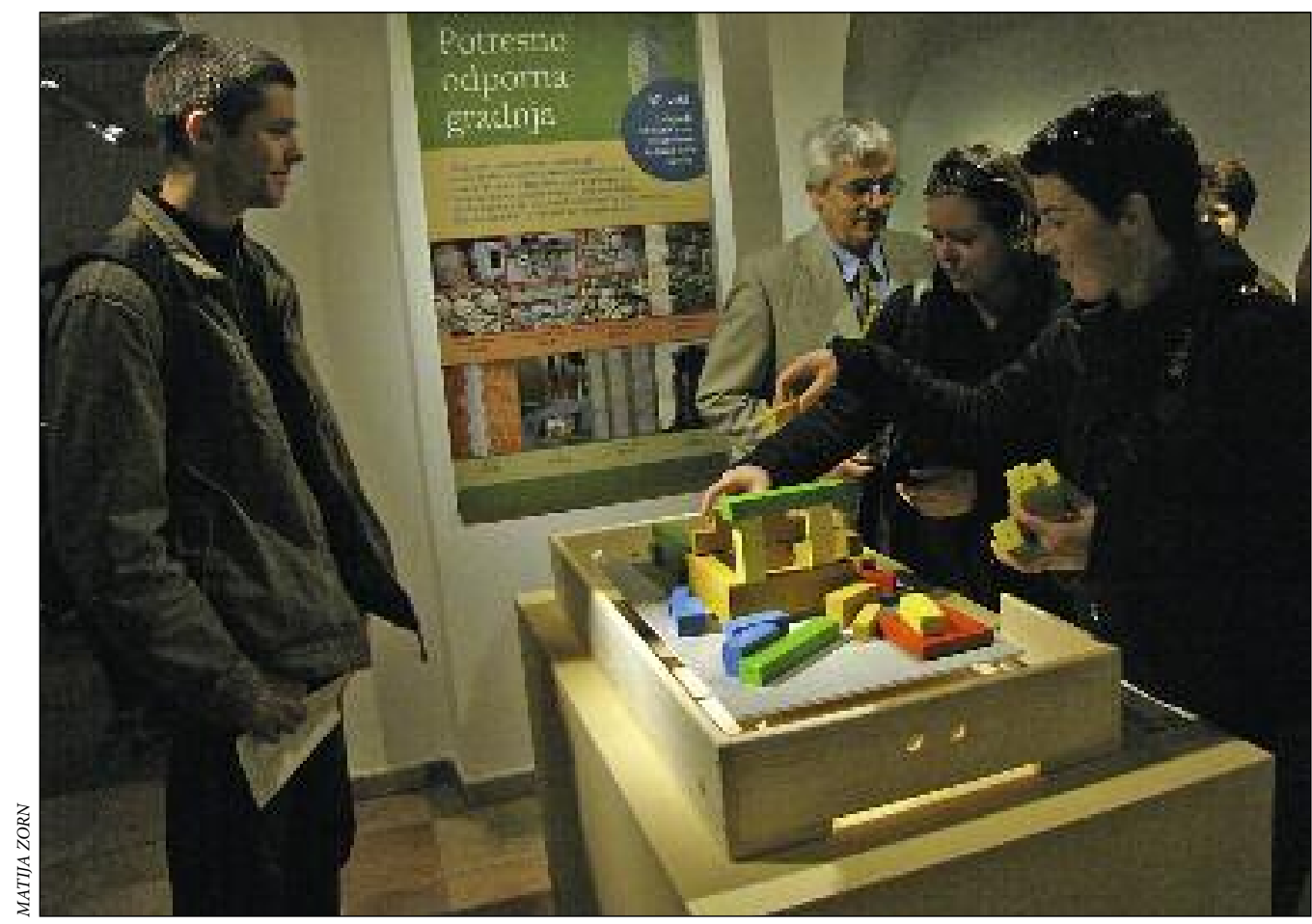

Slika 4: Učenje s poskušanjem je primeren način izobraževanja o naravnih nesrečah. Na sliki je z modelom ponazorjen učinek potresa na stavbe.

področju naravnih nesreč. Ugotavljata, da je na krajevni ravni splošni pristop za ublažitev pred naravnimi nesrečami povečanje prirojenih sposobnostih lokalnih skupnosti, saj so najbolj prožne skupnosti z izkušnjami in dobrim poznavanjem lokalnega okolja. Dejavnike, ki zmanjšujejo negativne učinke nevarnosti, je treba razumeti, kot sposobnost skupnosti, da se odzove in si opomore od naravne nesreče. Razdeljeni so na elemente prožnosti skupnosti ob naravni nesreči in na elemente zmanjšanja tveganja okolja. Opredelila sta naslednje kriterije za doseganje prožnosti skupnosti ob naravnih nesrečah:

- upravljanje z okoljskimi in naravni viri,

- zdravje in blaginja ljudi,

- trajnostno preživljanje (ang. livelihoods),

- socialno varstvo,

- finančni inštrumenti,

- fizična varnost, struktura in tehnična merila in

- načrtovanje upravljanja.

V prizadeti družbi so imeli največjo težo razumevanje delovanja narave, raznolikost življenjskih razmer na podeželju, socialna podpora in mreženje ter način odločanja $\mathrm{v}$ povezavi s prostorskim razvojem. Širše gledano so bili najpomembnejši kazalniki preventiva netrajnostne rabe zemljišč, zmanjšanje revščine, socialno varstvo za ranljive skupine ljudi in prostorsko načrtovanje, ki temelji na razumevanju naravnih nesreč.

Cohen s sodelavci (2013) so na podlagi študije v devetih malih do srednje velikih mestih ugotovili, da so za prožnost skupnosti pomembni: vodenje, učinkovitost skupnosti, pripravljenost na naravne nesreče, pripadnost kraju, zaupanje in družbena razmerja. 
Ainuddin in Routray (2012) ugotavljata, da prožnost nima standardne opredelitve niti jasnih metod ocenjevanja ter da je merjenje prožnosti izziv tako za znanstvenike kot oblikovalce politik, saj ni enotnih kazalnikov za oceno prožnosti skupnosti. Opredelila sta štiri vidike: potencialni vplivi, ranljivost, zaznavanje tveganja in prožnost. Prožnost deluje na individualni in na ravni skupnosti. Na podlagi vprašalnika ter analize ranljivosti in prožnosti potresne regije Beludžistan sta razvila družbeni okvir prožnosti in jo ocenila z različnimi kazalniki: socialni (stopnja izobrazbe, starost, zdravstvena oskrba, socialni kapital), ekonomski (lastništvo nepremičnin, zaposlenost, vir dohodkov), fizični (starost stavb, lega stavb) in institucionalni (blaženje učinkov, ozaveščanje, storitve občine). $\mathrm{V}$ pomoč pri upravljanju naravnih nesreč in tveganju pred potresi so jima bili tako primarni (opazovanje na terenu, ankete gospodinjstev in intervjuji) kot sekundarni podatki (knjige, članki, vladna poročila, seizmični zemljevidi, statistična poročila). Glavne informacije sta pridobila od vlade in drugih organizacij, ki so vključene v urbanistično načrtovanje. Pri intervjujih so bili vključeni naslednji dejavniki: družbeno-gospodarske značilnosti intervjuvancev, družbena, gospodarska, naravna in institucionalna prožnost.

Z regionalnega vidika je Schoutenova s sodelavci (2012) raziskala prožnost evropske politike razvoja podeželja. Glede na velike gospodarske, socialne in okoljske spremembe podeželskih območij, ki ovirajo trajnostni razvoj, je vse bolj nujen razvoj podeželskih politik, ki bodo podpirale prilagoditvene strategije deležnikov kot odgovor na naravne nesreče. Avtorji predlagajo koncept prožnosti pokrajine kot okvir za pomoč pri upravljanju sprememb na podeželju, saj upošteva kompleksnost družbenega in ekološkega sistema ter upošteva nepredvidljivo prihodnost, saj poudarja prilagoditvene pristope $\mathrm{k}$ upravljanju. Razvili so devet meril in izvedli študijo primera. K razumevanju prožnosti z vidika narav-

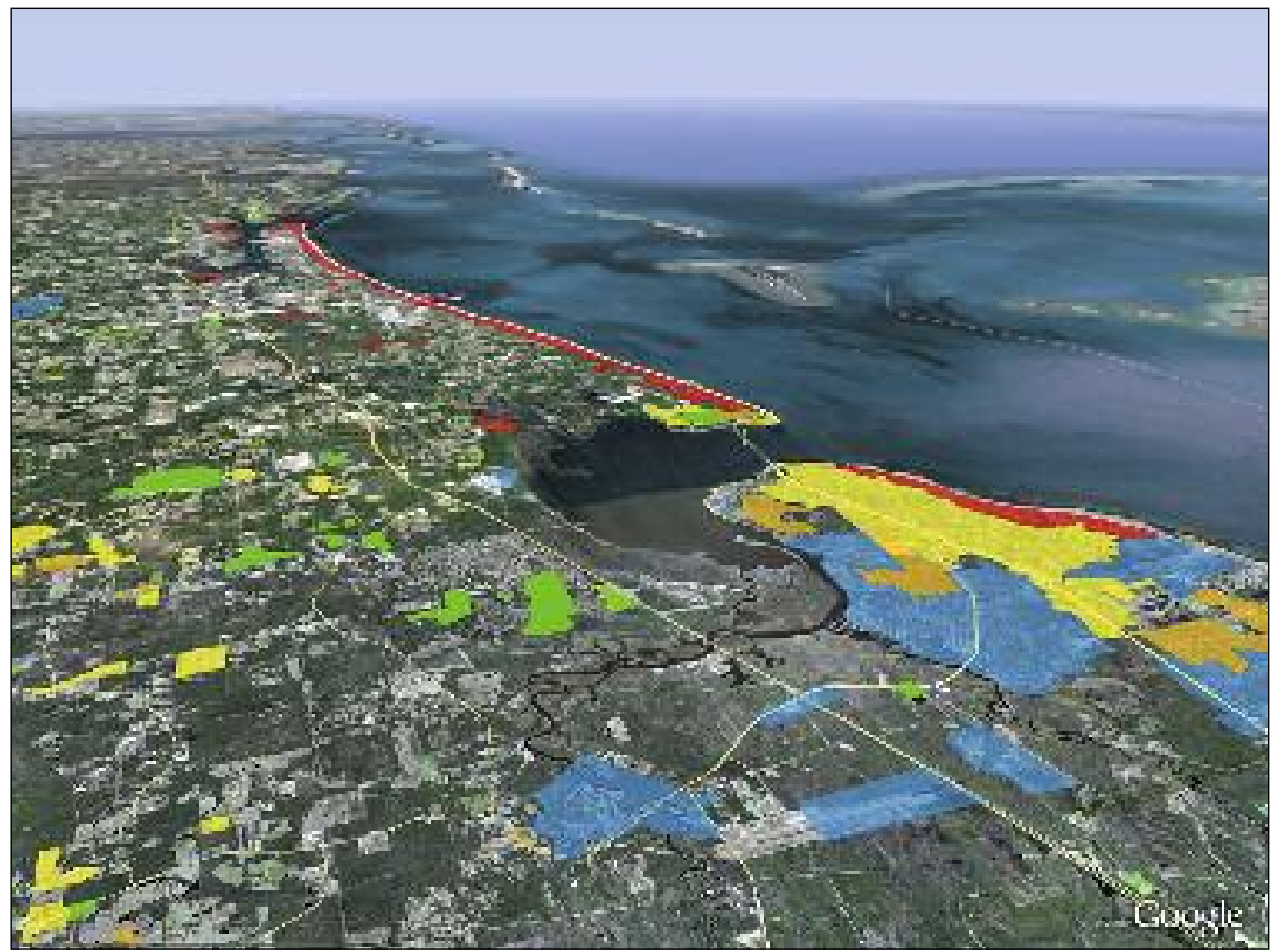

Slika 5: Sodobni pristopi, kot so geografski informacijski sistemi in računalniške aplikacije, omogočajo sprotno spremljanje pojavov in tako prispevajo $k$ večji prožnosti posameznika in družbe (Google ... 2010). 
nih nesreč največ prispevajo naslednja merila: upravljanje z naravnimi viri, trajnostno preživetje, socialno varstvo in pravilno prostorsko načrtovanje.

Francis in Bekera (2014) sta predstavila izračun prožnosti na primeru infrastrukturnih sistemov, kar smo v Sloveniji lahko opazovali na primeru žleda pozimi 2014. Prožnost sta analizirala z vidika absorpcijske in prilagoditvene sposobnosti sistema ter njegove zmožnosti za obnovo. Analizo sta opravila na podlagi električnega omrežja izmišljenega mesta Micropolis. Pri izračunu prožnosti sta vključila tudi časovni vidik. Čeprav je prožnost uporaben sistem, raznolikost v njeni uporabi otežuje njeno razlago in merjenje.

\section{Sklep}

Že kar številne raziskave prožnosti na področju naravnih nesreč kažejo, da je ocena prožnosti pokrajine kompleksen problem, do katerega lahko pristopimo na več različnih načinov. Do sedaj so se najbolj uveljavili uporaba kazalnikov in iz njih izračunanih indeksov. Tako zbrani oziroma sintetizirani podatki omogočajo prostorske in tudi časovne primerjave stanja določene pokrajine. Poglavitna težava je dostopnost do primernih podatkov na krajevni ali regionalni ravni.

Ocena prožnosti je uporabna metoda, saj obsega tako družbenogeografske kot naravnogeografske vsebine in omogoča kompleksno ter sintezno razumevanje procesov v pokrajini. Razlikujemo prožnost posameznika, družin, različnih skupnosti in družbe kot celote, predvsem slednje tudi v povezavi $\mathrm{z}$ naravnogeografskimi prvinami.

Družba se je naravnim nesrečam vedno poskušala prilagajati, z razvojem tehnologije pa je prišlo do želje po njihovem obvladovanju, ki ima svoje omejitve, zato je bolj primerno upravljanje z njimi. Sodelovanje skupnosti ob naravni nesreči privede do njene večje odpornosti, zato na sposobnost prilagoditve vplivajo pretekle izkušnje naravnih nesreč, zaznavanje tveganja in demografske značilnosti (Hartwell 2013), predvsem pa velika mobilnost prebivalstva. Z analizo prožnosti pokrajine $\mathrm{z}$ vidika naravnih nesreč lahko bolje upravljamo s prostorom, upoštevaje omenjene dejavnike in omejitve.

\section{Literatura}

Adger, N. 2000: Social and ecological resilience: Are they related. Progress in Human Geography 24-3. London. DOI: 10.1191/030913200701540465

Ainudin, S., Routray, J. K. 2012: Community resilience framework for an earthquake prone area in Baluchistan. International Journal of Disaster Risk Reduction 2. Amsterdam. DOI: 10.1016/ j.ijdrr.2012.07.003

Alexander, D. E. 2013: Resilience and disaster risk reduction: an etymological journey. Natural Hazards and Earth System Sciences 13. Katlenburg-Lindau. DOI: 10.5194/nhess-13-2707-2013

Birkmann, J. 2006: Measuring Vulnerability to Natural Hazards: Towards Disaster Resilient Societies. Tokyo.

Brundsen, D. 2001: A critical assessment of the sensivity concept in geomorphology. Catena 42, 2-4. Amsterdam. DOI: 10.1016/S0341-8162(00)00134-X

Bruneau, M., Chang, S. E., Eguchi, R. T., Lee, G. C., O'Rourke, T. D., Reinhorn, A. M., Shinozuka, M., Tierney, K., Wallace, W. A., von Winterfeldt, D. 2003: A framework to quantitatively assess and enhance the seismic resilience of communities. Earthquake Spectra 19-4. Oakland. DOI: 10.1193/1.1623497

Building our nation's resilience to natural disasters. Australian Business Roundtable for disaster resilience. Barton, 2013.

Campbell, F. C. 2008: Elements of Metalurgy and Engineering Alloys. Materials Park. 
Cannon, T. 2008: Reducing people's vulnerability to natural hazards. United Nations University Research Paper 34. Tokyo.

Chen, S. C., Ferng, J. W., Wang, Y. T., Wu, T. Y., Wang, J. J. 2008: Assessment of disaster resilience capacity of hillslope communities with high risk for geological hazards. Engineering Geology 98, 3-4. Amsterdam. DOI: 10.1016/j.enggeo.2008.01.008

Cohen, O., Leykin, D., Lahad, M., Goldberg, A., Aharonson-Daniela, L. 2013: The conjoint community resiliency assessment measure as a baseline for profiling and predicting community resilience for emergencies. Technological Forecasting and Social Change 80-9. New York. DOI: 10.1016/j.techfore.2012.12.009

Cutter, S. L., Barnes, L., Berry, M., Burton, C., Evans, E., Tate, E., Webb, J. 2008: A place-based model for understanding community resilience to natural disasters. Global Environmental Change B: Environmental Hazards 18-4. New York. DOI: 10.1016/j.gloenvcha.2008.07.013

Ellis, F. 1998: Household strategies and rural livelihood diversification. The Journal of Development Studies 35-1. London. DOI: 10.1080/00220389808422553

Folke, C., Carpenter, S., Elmqvist, T., Gunderson, L., Holling, C.S., Walker, B. 2002. Resilience and sustainable development: Building adaptive capacity in a world of transformations. Ambio 31-5. Stockholm.

Fortune, J., Peters, G. 1995: Learning From Failure - The Systems Approach. Chichester.

Francis, R., Bekera, B. 2014: A metric and frameworks for resilience analysis of engineered and infrastructure systems. Reliability Engineering and System Safety 12-1. Amsterdam. DOI: 10.1016/ j.ress.2013.07.004

Galderisi, A., Ferrara, F. F. 2013: Resilience. Encyclopedia of Natural Hazards. Dordrecht. DOI: 10.1007/978-1-4020-4399-4_292

Geršič, M., Repe, B., Blatnik, M., Brečko Grubar, V., Kovač, B., Pozvek, N., Seifert, A. 2014: Geografija in rastlinska sukcesija - izbrani primeri iz slovenskih pokrajin. Georitem 23. Ljubljana.

Google Earth Pro 4.3.7284.3916 (beta). Google. Santa Clara, 2010.

Hartwell, W. T. 2013: Community management of natural hazards. Encyclopedia of Natural Hazards. Dordrecht. DOI: 10.1007/978-1-4020-4399-4_72

Hewitt, K. 1997: Regions of Risk: Hazards, Vulnerability and Disasters. London.

Hewitt, K., Burton, I. 1971: The hazardousness of a place: A regional ecology of damaging events. Research Publication 6. Toronto.

Holling, C. S. 1973: Resilience and stability of ecological systems. Annual Review of Ecology and Systematics 4. Palo Alto. DOI: 10.1146/annurev.es.04.110173.000245

Holling, C. S. 2004: From complex regions to complex worlds. Ecology and Society 9-1. Wolfville.

Höppner, C., Buchecker, M., Bründl, M. 2010: Risk Communication and Natural Nazards. Medmrežje: http://caphaz-net.org/outcomes-results/CapHaz-Net_WP5_Risk-Communication2.pdf(15.9.2014).

Klein, R. J. T., Nicholls, R. J., Thomalla, F. 2003: Resilience to natural hazards: How useful is this concept? Global Environmental Change B: Environmental Hazards 5, 1-2. New York. DOI: 10.1016/ j.hazards.2004.02.001

Komac, B. 2009: Družbenogeografski spomin in naravnogeografski spomin na naravne nesreče. Acta geographica Slovenica 49-1. Ljubljana. DOI: 10.3986/AGS49107

Komac, B., Zorn, M., Kušar, D. 2012: New possibilities for assessing the damage caused by natural disasters in Slovenia: the case of the Real Estate Record. Geografski vestnik 84-1. Ljubljana.

Kozina, J. 2010: Transport accessibility to regional centres in Slovenia. Acta geographica Slovenica 50-2. Ljubljana. DOI: 10.3986/AGS50203

Kulig, J., Hanson, L. 1996: Discussion and expansion of the concept of resiliency: Summary of a think tank. Leithbridge.

Lu, P., Stead, D. 2013: Understanding the notion of resilience in spatial planning: A case study of Rotterdam, the Nederlands. Cities 35. Guildford. DOI: 10.1016/j.cities.2013.06.001 
Lunino, F. 2005: Sequence of instability processes triggered by heavy rainfall in the Northern Italy. Geomorphology 66-1. New York. DOI: 10.1016/j.geomorph.2004.09.010

Major, J. J. 2003: Extreme events and geomorphic resilience insight from response to the cataclysmic 1980 Mount St. Helens eruption. American Geophysical Union Abstract H42J06. Vancouver.

Manyena, S. B. 2006: The concept of resilience revisited. Disasters 30-4. Oxford. DOI: 10.1111/ j.0361-3666.2006.00331.x

Martin, R. 2012: Regional economic resilience, hysteresis and recessionary shocks. Journal of Economic Geography 12-1. Oxford. DOI: 10.1093/jeg/lbr019

Mavhura, E., Manyena, S. B., Collins, A. E., Manatsa, D. 2013: Indigenous knowledge, coping strategies and resilience to floods in Muzarabani, Zimbabwe. International Journal of Disaster Risk Reduction 5. Amsterdam. DOI: 10.1016/j.ijdrr.2013.07.001

Mikoš, M., Fazarinc, R., Ribičič, M. 2006: Sediment production and delivery from recent large landslides and earthquake induced rock falls in the Upper Soča River Valley, Slovenia. Engineering Geo$\operatorname{logy} 86,2-3$. Oxford. DOI: 10.1016/j.enggeo.2006.02.015

Natek, K. 2002: Ogroženost zaradi naravnih procesov kot strukturni element slovenskih pokrajin. Dela 18. Ljubljana. DOI: 10.4312/1350

Orencio, P. M., Fujii, M. 2013: A localized disaster resilience index to assess coastal communities based on an analytic hierarchy process (AHP). International Journal of Disaster Risk Reduction 3. Amsterdam. DOI: 10.1016/j.ijdrr.2012.11.006

Paton, D., Johnston, D. M. 2006: Disaster Resilience: An Integrated Approach. Springfield.

Perrow, C. 1999: Normal Accidents: Living With Highrisk Technologies. Princeton.

Petek, F., Gabrovec, M. 2002: A methodology for assessing the change in land use in Slovenia from the viewpoint of sustainable development. Land Use/Land Cover Changes in the Period of Globalization. Praga.

Price-Robertson, R., Knight, K. 2012: Natural disasters and community resilience. Child Family Community Australia Paper 3. Melbourne.

Raco, M., Street, E. 2012: Resilience planning, economic change and the politics of postrecession development in London and Hong Kong. Urban Studies 49-5. Abingdon. DOI: 10.1177/0042098011415716

Rose, A., Krausmann, E. 2013: An economic framework for the development of a resilience index for business recovery. International Journal of Disaster Risk Reduction 5. Amsterdam. DOI: 10.1016/ j.ijdrr.2013.08.003

Rouillard, J. J., Reeves, A. D., Heal, K. V., Ball, T. 2014: The role of public participation in encouraging changes in rural landuse to reduce flood risk. Land Use Policy 38. New York. DOI: 10.1016/ j.landusepol.2014.01.011

Schelfaut, K., Pannemans, B., van der Craats, I., Krywkow, J., Mysiak, J., Cools, J. 2011: Bringing flood resilience into practice: the FREEMAN project. Environmental Science and Policy 14-7. Exeter. DOI: 10.1016/j.envsci.2011.02.009

Schouten, M. A. H., van der Heide, C. M., Heijman W. J. M., Opdam, P. F. M. 2012: A resilience based policy evaluation framework: Application to European rural development policies. Ecological Economics 81. New York. DOI: 10.1016/j.ecolecon.2012.07.004

Tobin, G. 1999: Sustainability and community resilience: The holy grail of hazard planning? Global Environmental Change B: Environmental Hazards 1-1. New York. DOI: 10.1016/S1464-2867(99)00002-9

Turconi, L., Nigrelli, G., Conte, R. 2014: Historical datum as a basis for new GIS application to support civil protection services in NW Italy. Computers and Geosciences 66. Oxford. DOI: 10.1016/ j.cageo.2013.12.008

Walker, B., Carpenter, S., Anderies, J., Abel, N., Cumming, G., Janssen, M., Lebel, L., Norberg, J., Peterson G. D., Pritchard, R. 2002: Resilience management in social-ecological systems: A working hypothesis for a participatory approach. Ecology and Society 6-1. Wolfville. 
Weichselgartner, J., Kelman, I. 2014: Geographies of resilience - challenges and opportunities of a descriptive concept. Progress in Human Geography. London. DOI: 10.1177/0309132513518834

Woodroffe, C. D. 2006: The Natural Resilience of Coastal Systems: Primary Concepts. Woolongong.

Zehetmair, S. 2012: Societal aspects of vulnerability to natural hazards. Raumforschung und Raumordnung 70-4. Heidelberg.

Zhou, H., Wang, J., Wan, J., Jia, H. 2010: Resilience to natural hazards: A geographic perspective. Natural Hazards 53-1. Dordrecht. DOI: 10.1007/s11069-009-9407-y

Zorn, M., Komac, B. 2009: Nekateri učinki bojevanja na naravno pokrajino. Geografski vestnik 81-2. Ljubljana.

Zorn, M., Komac, B. 2011: Škoda zaradi naravnih nesreč v Sloveniji in svetu med letoma 1995 in 2010. Acta geographica Slovenica 51-1. Ljubljana. DOI: 10.3986/AGS51101

Zorn, M., Komac, B., Kumelj, Š. 2012: Mass movement susceptibility maps in Slovenia: The current state. Geografski vestnik 84-1. Ljubljana.

\section{Summary: Some thoughts on the concept of resilience in geography of natural hazards}

(translated by Nataša Pregl)

Based on geographical conceptions, natural hazards are an integral part of the landscape and not exceptional occurrences or malfunctions of nature and society. Throughout history, this has been proved by society's constant adaptation to the ever-changing natural conditions. In the period before the industrial revolution, society had limited but also effective ways of adjusting to natural events, e.g.: land treatment and controlled burning of forests to create fields, construction of terraced landscapes and irrigation systems, mineral extraction and energy generation. The developments in technology triggered a shift from adaptation to management. The present landscape reflects its entire evolution so far, including the various forms of coexistence with natural hazards.

Nevertheless, natural hazards cause substantial damage in modern, »well developed « European countries as well, mainly due to the inadequate planning which does not take into account natural processes and allows activities in hazardous areas. The society is not prepared to the fact that magnitude of natural processes is being changed by climate change.

One of the main challenges of Slovenian society is how to reduce the financial consequences of natural hazards in the long term. Since independence of Slovenia (2001-2008), natural hazards have caused direct damage worth 1.6 billion EUR. On average, this is approximately 50 euro per citizen per year. Total economic damage, however, is about five times higher.

The concept of resilience is a rather new in science, however in a broader sense it has been known for centuries. The term itself was applied by e.g. Ovid, Seneca the Elder, Pliny the Elder and mainly by St. Jerome in his proverbs. In modern science, resilience is seen as a distinctly interdisciplinary scientific approach. The origin of the word is the Latin word resilire, which means to bounce back or jump off. It is used to describe the ability to adapt to the natural conditions as well as to the financial, organisational or defence circumstances.

In natural sicences the term was first applied in ecology and described by Holling as »the level of an ecosystem's ability to absorb change and further exist " or "the maintenance of relationships within an ecosystem. "Resilience is also described as the ability of a system to maintain its current form, absorb shocks or disturbances or to adapt to the disturbance and at the same time keep its essential characteristics intact while still maintaining its function. Some researches pointed out the self-organisational resilience of systems and is included in a complex response of geomorphic system. 
By Hewitt, resilience is essentially a "geographic category «. It is therefore not surprising that from its initial use in ecology, physics, civil engineering and psychiatry, the concept has recently expanded mostly to the field of natural hazards. It has thus acquired a social-geographical meaning as well.

From the social point of view, resilience is "the response of social communities, institutions or economic systems to changes and adaptations in the direction of further existence". Social resilience in a landscape is mainly seen in participatory planning of activities and use of space in spatial, regional and urban planning as well as in different other ways of coexisting with natural hazards.

As in geography, the concept of resilience is based on the complexity of landscape as a social and natural system, taking into account the perspective of both space and time. In this way it may be a good way of tackling the problem of natural hazards and can be used for the assessment of the adaptation (resilience) level in certain regions to improve the management of natural hazards. The paper presents some ways of resilience assessment, by various indicators and different indices.

Due to fast changes of society the only possibility of long-term positive changes is in adapting the social components of a geographical system and in strengthening the resilience of the society to the irregular functioning of natural hazards seen as natural disasters. The main goal of strengthening the system's resilience is enabling its further functioning despite any exterior disruptions or interior weaknesses. The idea of resilience and its assessment is still new in contemporary hazard-related literature in Slovenia, therefore the aim of the paper is to present some basic thoughts about it. 